\title{
Role of Peroral Endoscopic Myotomy in Geriatric Patients with Achalasia: A Systematic Review and Meta-Analysis
}

\author{
Chunyu Zhong ${ }^{a}$ Shu Huang ${ }^{b}$ Huifang Xia ${ }^{a}$ Shali Tan ${ }^{a}$ Muhan Lü \\ Yan Peng ${ }^{\text {a }}$ Xiaowei Tang ${ }^{\text {a }}$ \\ aDepartment of Gastroenterology, Affiliated Hospital of Southwest Medical University, Luzhou, China; \\ bDepartment of Gastroenterology, the People's Hospital of Lianshui, Huaian, China
}

\section{Keywords}

Achalasia $\cdot$ Peroral endoscopic myotomy $\cdot$ Geriatric patients $\cdot$ Systematic review $\cdot$ Meta-analysis

\begin{abstract}
Background: Peroral endoscopic myotomy (POEM) is a particularly attractive intervention for achalasia. Presently, POEM has been reported to be effective and safe for achalasia in geriatric patients. Herein, this systematic review was conducted to explore the role of POEM in geriatric patients with achalasia. Method: PubMed, Embase, and Cochrane Library were searched to identify studies evaluating the clinical outcome of POEM in geriatric patients with achalasia during January 2009 to October 2020. The primary outcomes were technical and clinical success. Secondary outcomes included postoperative Eckardt score, lower esophageal sphincter (LES) pressure, adverse events, and clinical reflux. Results: There were 7 studies with a total of 469 geriatric patients, and the pooled technical success of POEM treatment was $98.1 \%$ (95\% confidence interval [CI], 95.1-99.3\%), and the pooled clinical success was $92.5 \%(95 \% \mathrm{Cl}, 89.3-94.8 \%)$. After POEM, the Eckardt score significantly decreased by 6.09 points $(95 \% \mathrm{Cl}, 5.44-6.74, p<0.00001)$, and the LES pressure significantly reduced by $13.53 \mathrm{~mm} \mathrm{Hg}(95 \% \mathrm{Cl}, 5.14$
\end{abstract}

$21.91, p=0.002)$. The pooled adverse events rate was $9.0 \%$ (95\% Cl, 4.3-17.9\%), and the post-POEM clinical reflux rate was $17.4 \%$ (95\% Cl, 12.9-23.2\%). Conclusion: Our current study demonstrated that POEM was an effective and safe technique for achalasia in geriatric patients.

(C) 2021 S. Karger AG, Basel

\section{Introduction}

Achalasia is an esophageal motility disorder, characterized by insufficient relaxation of the lower esophageal sphincter (LES), resulting in obstructed bolus transport and stasis of food in the esophagus $[1,2]$. It occurs very rarely, with an estimated incidence rate of $0.77-1.35$ per 100,000 population and a prevalence of $1.41-4.60$ per 100,000 population. Achalasia can occur in all patient age-groups, with highest incidence in the seventh decade of life [3-5]. The most common clinical symptoms for achalasia include dysphagia, regurgitation, aspiration pneumonia, chest pain, and weight loss [6]. The course of this disease is generally chronic, progressive dysphagia

Chunyu Zhong, Shu Huang and Huifang Xia contributed equally to this study. karger@karger.com

www.karger.com/ddi

Karger ${ }^{\prime \prime}=$
(C) 2021 S. Karger AG, Basel
Correspondence to:

Xiaowei Tang, solitude5834@ hotmail.com 
and weight loss over several months to years, which significantly impairs life quality. Therefore, proper treatment is of vital importance for achalasia.

Current therapeutic options include medical treatment, botulinum toxin injection, pneumatic dilation, peroral endoscopic myotomy (POEM), and laparoscopic Heller myotomy (LHM). LHM can achieve a relatively lasting effect but limited by the risk of perforation (4-7\%) or surgical morbidity in geriatric patients [7-9]. Recently, a novel less invasive technique, POEM has been widely accepted for treating achalasia with an excellent safety profile, durability, and efficacy in adults [10-12]. Whether the same success can be achieved in geriatric patients requires further exploration. At present, some articles have explored the safety and efficacy of POEM in geriatric patients [13-19]. Therefore, we conducted this metaanalysis to summarize the safety and effectiveness of POEM in geriatric patients with achalasia.

\section{Methods}

\section{Search Strategy}

We conducted a systematic literature search in PubMed, Embase, and Cochrane Library covering the period from January 2009 to October 2020. The key words included "achalasia," "POEM," "per-oral endoscopic myotomy," and "peroral endoscopic myotomy." These words were used in all possible combinations to obtain the maximal number of studies (see online suppl. Table 1; see www.karger.com/doi/10.1159/000516024 for all online suppl. material). The word "geriatric" was not involved in our search to ensure a thorough search of the research available for POEM. This systematic review was carried out according to the guidelines of the Preferred Reporting Items for Systematic Reviews and MetaAnalyses (PRISMA) [20]. Our research does not require IRB approval and written consent.

\section{Study Selection}

The title and abstract of identified studies were first reviewed. If the studies were still eligible after screening, the full-text articles were reviewed in accordance with our inclusion and exclusion criteria. The inclusion criteria were as follows: (1) population: geriatric patients diagnosed with achalasia and aged $\geq 65$ years; (2) intervention: POEM; and (3) outcome: technical and clinical success, Eckardt score, LES pressure, adverse events, and clinical reflux. Animal studies, case reports with $<5$ patients, reviews and metaanalyses, duplicates, and studies that did not provide the available data for meta-analysis were excluded. Two reviewers independently conducted the article screening and data extraction. Any differences between reviewers were resolved by discussing with a third reviewer.

\section{Data Extraction and Definition}

The following data were extracted from the included articles: characteristics of the study (first author, year of publication, country, study duration, study design, number of patients, age, and gen- der), preoperative and operative data (duration of symptoms, number of treatment-naive patients, achalasia type, American Society of Anesthesiology Physical Status Classification System [ASA] scores, sigmoid-shaped esophagus, length of myotomy, operative time, length of hospital stay, and type of myotomy), and clinical outcomes (technical success rate, clinical success rate, preand postoperative Eckardt scores, pre- and postoperative LES pressure, adverse events, post-POEM clinical reflux, and follow-up time). The type of myotomy included full-thickness myotomy or selective circular bundles myotomy. Technical success was defined as completion of the whole POEM procedure. Clinical success was defined as an Eckardt score $\leq 3$ during follow-up after the POEM procedure. The severity of adverse events was graded according to the American Society for Gastrointestinal Endoscopy (ASGE) lexicon [21]. Clinical reflux included symptomatic reflux and reflux esophagitis.

\section{Assessment of Study Quality}

Quality assessment was done by 2 reviewers independently using the National Institutes of Health (NIH) quality assessment tool, which was suitable for before-after studies with no control group [22]. Quality assessment of studies is highlighted in online suppl. Table 2.

\section{Statistical Analysis}

The statistical analysis was conducted using Review Manager 5.3 and Comprehensive Meta-Analysis software version 2, with a significance degree set at $p<0.05$. The random-effects model was applied to this meta-analysis because the random-effects model provides more conservative estimations and was considered to be more realistic in this scenario [23]. For meta-analyses of dichotomous variables, such as technical success rate, clinical success rate, adverse events, and clinical reflux rate, the pooled event rates with a $95 \%$ confidence interval (CI) were calculated. For meta-analyses of continuous variables, including Eckardt scores and LES pressure, the mean difference with $95 \%$ CI was calculated. If study data are expressed as median and range, they were converted to standard deviation before analysis. Heterogeneity was assessed using $\mathrm{I}^{2}$ statistics. The $I^{2}$ score values of $0-30,30-50,50-75$, and 75$100 \%$ were reflective of low, moderate, substantial, and high heterogeneity, respectively, according to the Cochrane Handbook for Systematic Reviews of Interventions [24]. Funnel plots was used to evaluate publication bias.

\section{Results}

\section{Characteristics of Included Studies}

Figure 1 shows the PRISMA flow diagram of our literature search. In summary, the initial search revealed 3,220 studies, of which 2,712 were screened for eligibility criteria after removing duplicates. After screening the titles and abstracts, 2,698 studies were excluded according to the predefined criteria and 14 full-text studies fulfilled criteria for eligibility assessment. Finally, 7 studies that fulfilled eligibility criteria were included for qualitative analysis (meta-analysis) [13-19]. 
Fig. 1. PRISMA statement of the study. PRISMA, Preferred Reporting Items for Systematic Reviews and Meta-Analyses.

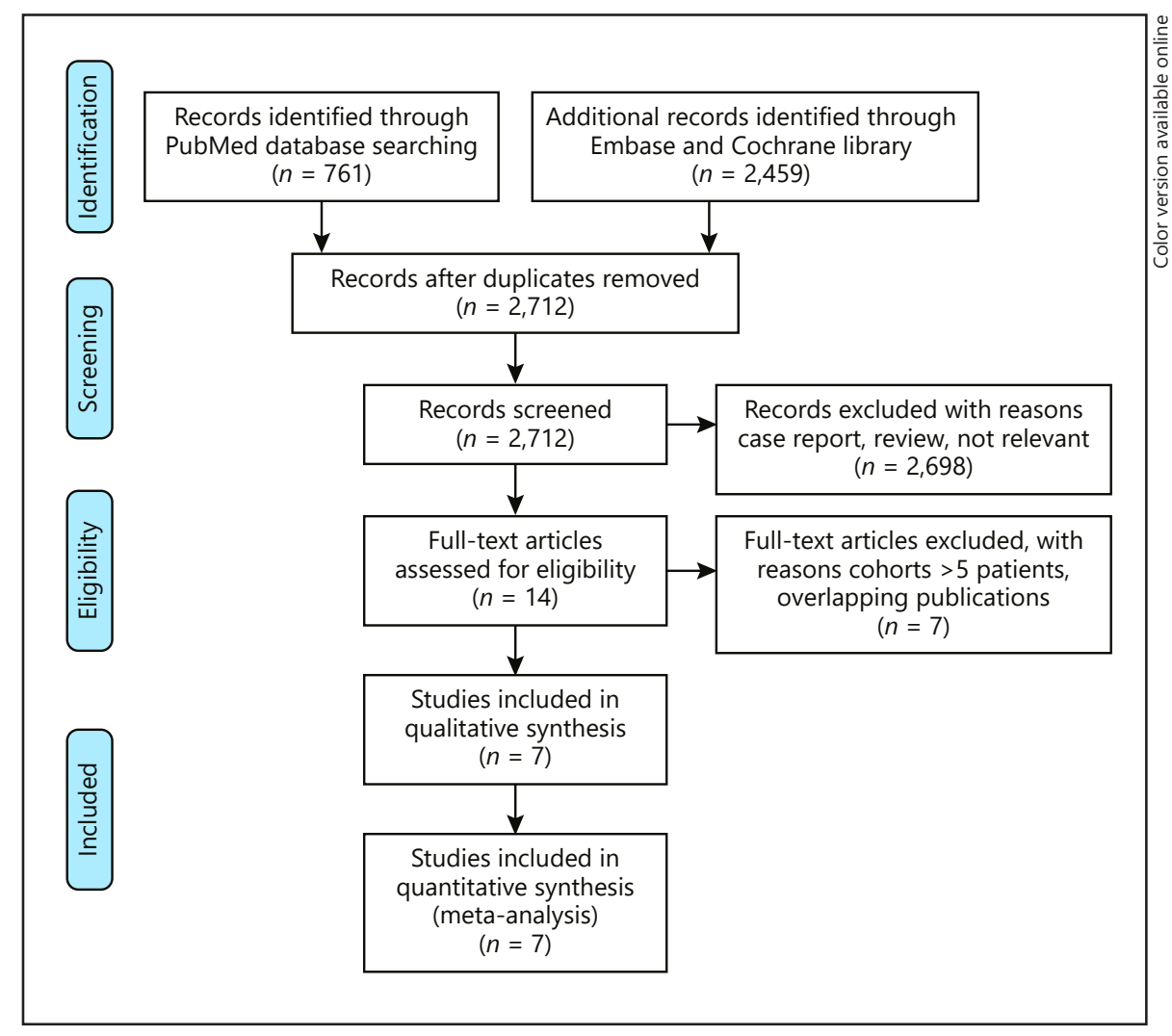

Table 1 shows the baseline characteristics of the included studies. Among them, 3 studies were performed in the United States, 2 in China, 1 in Italy, and 1 in Japan. And these studies were published between 2016 and 2020 . The included studies recruited patients from 2010 to 2019. All included studies were retrospective cohort studies, with 2 of the articles published as conference abstracts. All studies explored the efficacy and safety of POEM on geriatric patients.

\section{Patients Baseline Characteristics}

Of the 469 geriatric patients included in our studies, $235(50.1 \%)$ patients were male. The mean age ranged from 67.9 to 84 years, and the duration of symptoms ranged from 5.5 to 30 months. Treatment-naiveness was reported in 5 articles, and there were $58.0 \%$ (185/319) of patients without receiving previous interventions before POEM. Achalasia types were reported in 2 studies, among which 18 patients were type I, 43 were type II, and 13 were type III. A sigmoid-shaped esophagus was reported in 4 studies, and there were $18.6 \%(45 / 242)$ of patients with a sigmoid-shaped esophagus (Table 1,2).

\section{Operative Data}

Table 2 shows the detailed operative data of the POEM procedure. The mean myotomy length was reported in 6 studies, which ranged from 10 to $14.5 \mathrm{~cm}$. The mean operative time was reported in 4 studies, which ranged from 50 to $103.7 \mathrm{~min}$. And the hospital stay was reported in 5 studies, which ranged from 1 to 9.8 days. The type of myotomy was reported in 3 studies, in which full-thickness myotomy was applied in 137 geriatric patients and circular myotomy in 99 geriatric patients.

\section{Clinical Outcome}

Table 3 shows the clinical outcomes of POEM for achalasia in geriatric patients. Of all included studies, 5 studies reported postoperative Eckardt scores and 4 studies reported postoperative LES pressure. The pooled technical success of POEM treatment for achalasia was $98.1 \%$ (95\% confidence interval [CI], 95.1-99.3\%, $I^{2}=29.795 \%$ ) (Fig. 2a), and the pooled clinical success was $92.5 \%$ (95\% CI, 89.3-94.8\%, $I^{2}=0 \%$ ) (Fig. 2b).

The follow-up time was reported in 5 studies, which ranged from 2.4 to 41 months. In order to compare the differences of the clinical outcomes in different follow-up 
Table 1. Baseline characteristics of included studies

\begin{tabular}{lllllcrr}
\hline Study & $\begin{array}{l}\text { Year of } \\
\text { publication }\end{array}$ & Country & Duration & Study design & $\begin{array}{l}\text { Patient, } \\
n\end{array}$ & $\begin{array}{l}\text { Age, } \\
\text { years }\end{array}$ & $\begin{array}{l}\text { Gender } \\
(\mathrm{M}: \mathrm{F})\end{array}$ \\
\hline Wang et al. [13] & 2016 & China & Jan 2010-Dec 2015 & Retrospective & 21 & $67.9 \pm 4.3$ \\
Chen et al. [14] & 2018 & The USA & Jan 2010-Jan 2016 & Retrospective & 76 & $84 \pm 3.2$ \\
Landi et al. [15] & 2018 & Italy & May 2011-Apr 2017 & Retrospective* & 88 & $72.2 \pm 4.7$ \\
Liu et al. [16] & 2019 & China & Aug 2010-Dec 2017 & Retrospective & 139 & $70.22 \pm 5.68$ \\
Klair et al. [17] & 2019 & The USA & Dec 2014-Oct 2018 & Retrospective* & 62 & $72.3 \pm 5.7$ \\
Abe et al. [18] & 2020 & Japan & Apr 2015-Mar 2019 & Retrospective & 28 & $39: 49$ \\
Sanaka et al. [19] & 2020 & The USA & Apr 2014-May 2019 & Retrospective & 55 & $74^{\#}$ (IQR 70-79) 31:24 \\
\hline
\end{tabular}

M:F, male to female; IQR, interquartile range. * Published conference abstracts. ${ }^{*}$ Median.

periods, we performed a subgroup analysis, in which the follow-up time was divided into less than 1 year, 1-3 years, and greater than 3 years (online suppl. Table 2). The pooled clinical success rate of POEM for geriatric patients with achalasia at different follow-up points was 95.4\% (95\% CI, 91.9-97.4\%, $I^{2}=0 \%$ ), 92.3\% (95\% CI, 86.9-95.6\%, $I^{2}=0 \%$ ), and 92.8\% (95\% CI, 85.2-96.6\%, $I^{2}=0 \%$ ), respectively (online suppl. Fig. 1). After POEM, the Eckardt score in geriatric patients was significantly decreased by 6.09 points (95\% CI, 5.44-6.74, $p<0.00001$, $\left.I^{2}=83 \%\right)$ (Fig. 3a), and the LES pressure was significantly reduced by $13.53 \mathrm{~mm} \mathrm{Hg}$ (95\% CI, 5.14-21.91, $p=$ $0.002, I^{2}=97 \%$ ) (Fig. 3b).

\section{Adverse Events and Clinical Reflux}

According to ASGE lexicon, the adverse events were classified as mild, moderate, severe, and fatal. As shown in online suppl. Table 3 , a total of 45 adverse events were reported in geriatric patients. Most of the adverse events were mild $(35.5 \%, 16 / 45)$ or moderate $(60.0 \%, 27 / 45)$, and only 2 events were graded as severe $(4.4 \%, 2 / 58)$. There was no fatal event. Overall, as shown in Figure 2c, the pooled adverse event rate related to POEM was 9.0\% (95\% CI, $4.3-17.9 \%, I^{2}=74.612 \%$ ). There were 4 studies that reported the clinical reflux. After POEM, a total of $44 / 256$ geriatric patients experienced clinical reflux, and the pool rate was $17.4 \%\left(95 \% \mathrm{CI}, 12.9-23.2 \%, I^{2}=\right.$ 10.128\%) (Fig. 2d).

\section{Quality of Included Studies and Publication Bias}

Online suppl. Table 4 shows the quality assessment of each study according to the NIH quality assessment tool. Of 7 involved studies, only one study [14] was of good quality and the remaining 6 studies [13,15-19] were of fair quality. There was symmetry in our funnel plots, which suggested that publication bias could be generally not considered (online suppl. Fig. 2).

\section{Discussion}

It has been reported that there is a peak in the incidence of achalasia among the geriatric population. Therefore, it is of vital importance to treat achalasia in geriatric patients [3-5]. The aim of therapy for achalasia is to reduce the LES pressure, with relieving symptoms, improving esophageal emptying, and preventing the development of mega-esophagus [25]. Medical treatment has been largely abandoned because of its poor efficacy and significant side effects [26]. LHM is the most successful treatment for geriatric patients without surgical contraindications [27]. However, LHM is an invasive procedure, accompanied by operative complications, not even suitable for these geriatric patients with high risk of anesthesia and operation. Therefore, endoscopic treatment is recommended as the first-line choice for geriatric patients with comorbidities [28]. Botulinum toxin injection and endoscopic pneumatic dilation are effective and safe in geriatric patients, but the effect is not long-lasting and often need repeated treatment $[29,30]$. POEM has been a promising novel endoscopic treatment for achalasia with excellent outcomes $[31,32]$. But it is unclear whether POEM is an appropriate and safe treatment modality for geriatric patients. Currently, our systematic review and meta-analysis revealed that (a) the pooled technical success of POEM for geriatric patients was $98.1 \%$ and the pooled clinical success was $92.5 \%$ (long-term efficacy was $92.8 \%$ at 3 -year follow-up), and (b) the pooled adverse 

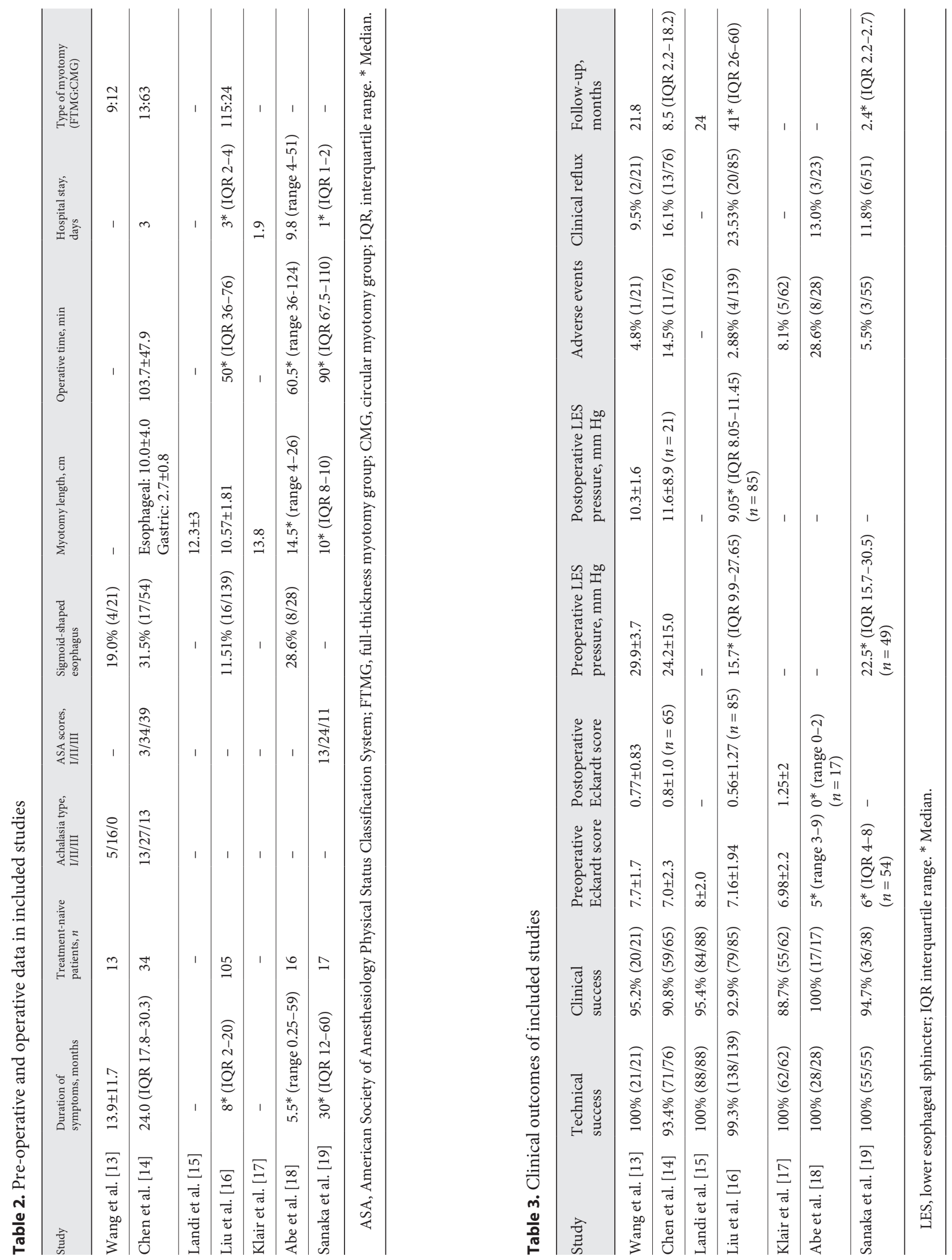
a Technical success

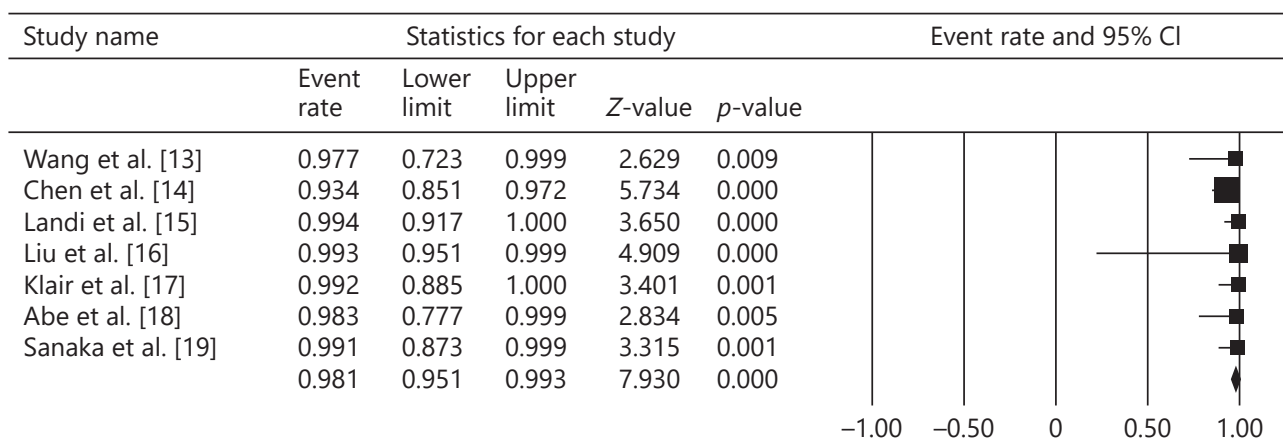

b Clinical success

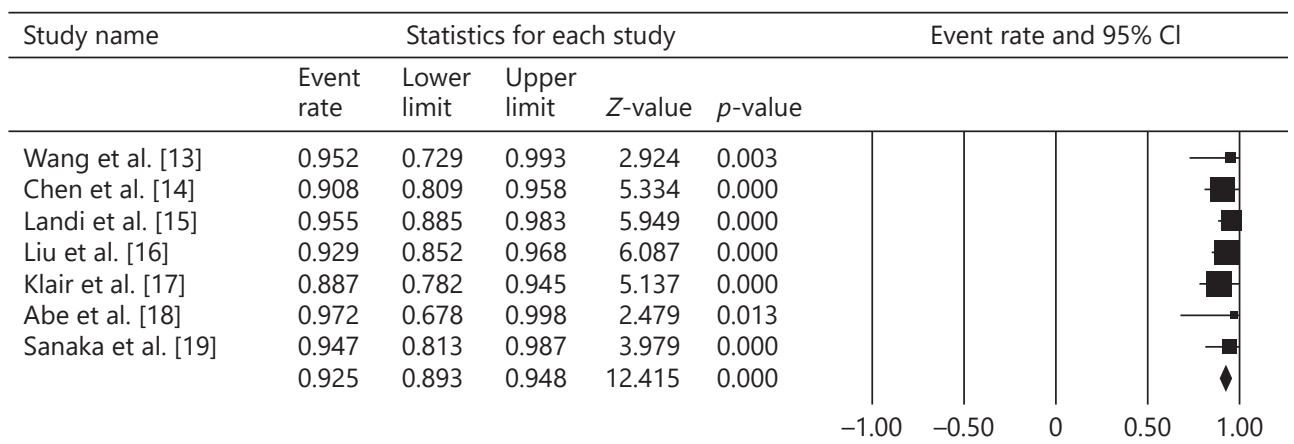

C Adverse events

\begin{tabular}{|c|c|c|c|c|c|c|c|c|c|}
\hline \multirow[t]{2}{*}{ Study name } & \multicolumn{5}{|c|}{ Statistics for each study } & \multicolumn{4}{|c|}{ Event rate and $95 \% \mathrm{Cl}$} \\
\hline & $\begin{array}{l}\text { Event } \\
\text { rate }\end{array}$ & $\begin{array}{l}\text { Lower } \\
\text { limit }\end{array}$ & $\begin{array}{l}\text { Upper } \\
\text { limit }\end{array}$ & $Z$-value & $p$-value & & & & \\
\hline Wang et al. [13] & 0.048 & 0.007 & 0.271 & -2.924 & 0.003 & & & & \\
\hline Chen et al. [14] & 0.145 & 0.082 & 0.243 & -5.449 & 0.000 & & & & \\
\hline Liu et al. [16] & 0.029 & 0.011 & 0.074 & -6.936 & 0.000 & & & & \\
\hline Klair et al. [17] & 0.081 & 0.034 & 0.180 & -5.218 & 0.000 & & & & \\
\hline Abe et al. [18] & 0.286 & 0.150 & 0.476 & -2.190 & 0.028 & & & & \\
\hline \multirow[t]{3}{*}{ Sanaka et al. [19] } & 0.055 & 0.018 & 0.156 & -4.804 & 0.000 & & & & \\
\hline & 0.090 & 0.043 & 0.179 & -5.727 & 0.000 & & & & \\
\hline & & & & & & -1.00 & -0.50 & 0.50 & 1.00 \\
\hline
\end{tabular}

d Clinical reflux

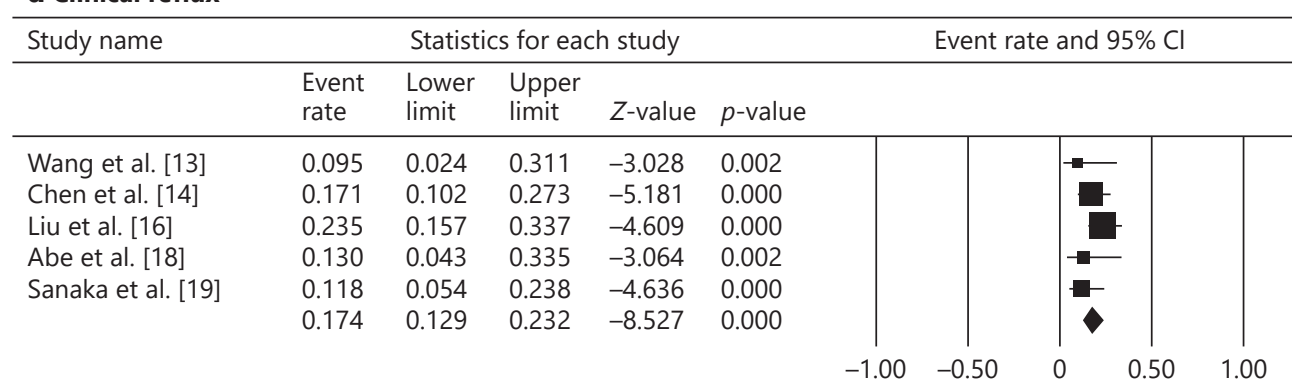

Fig. 2. a Forest plot of technical success of POEM for achalasia in geriatric patients. b Forest plot of overall clinical success of POEM for achalasia in geriatric patients. c Forest plot of the adverse events rate related to POEM in geriatric patients with achalasia. $\mathbf{d}$ Forest plot of the clinical reflux rate related to POEM in geriatric patients with achalasia. POEM, peroral endoscopic myotomy; CI, confidence interval.

Role of POEM for Achalasia in Geriatric Patients
Dig Dis 2022;40:106-114

DOI: $10.1159 / 000516024$ 


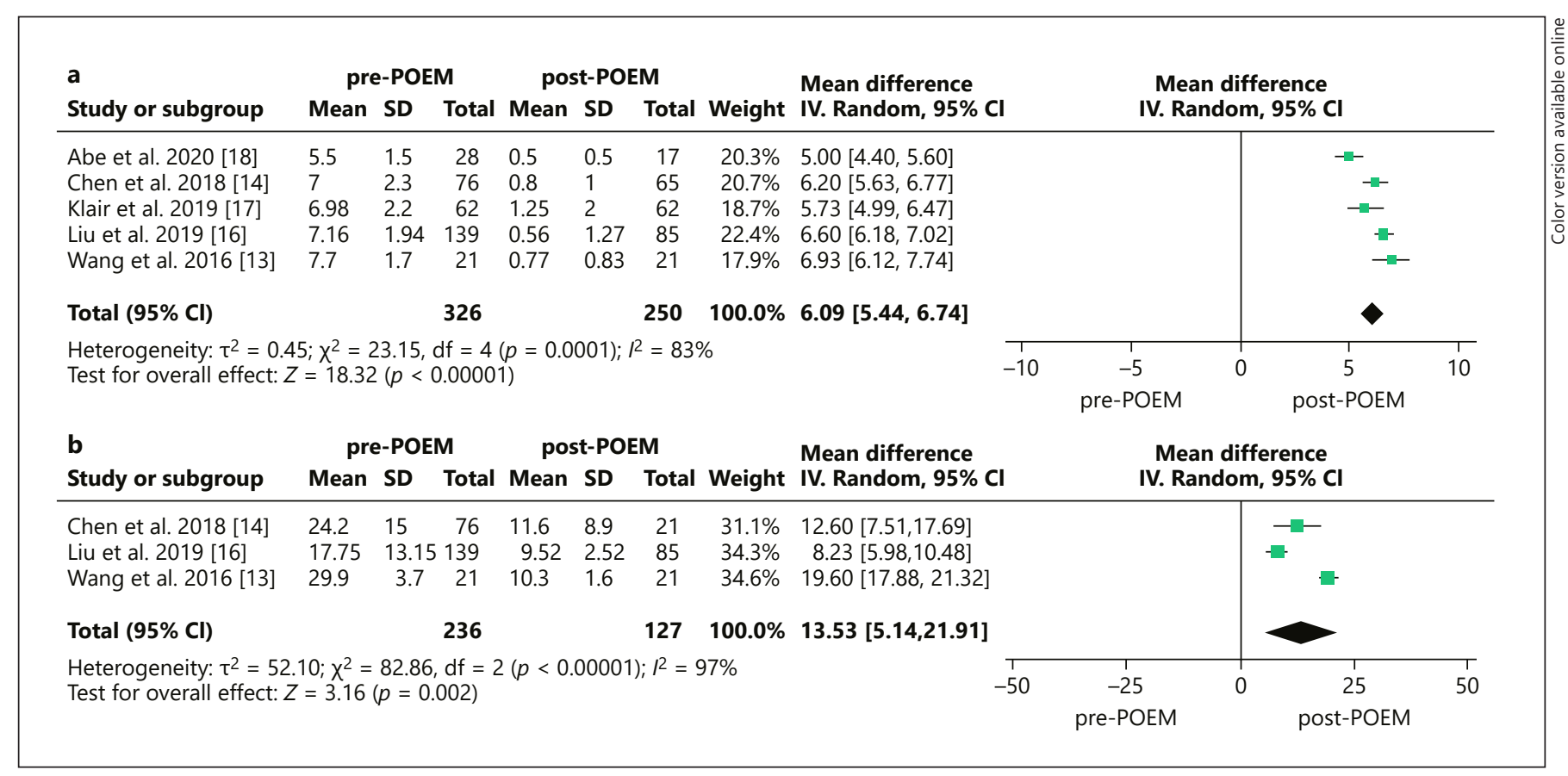

Fig. 3. a Meta-analysis of the changes of the Eckardt score after POEM in geriatric patients with achalasia. b Metaanalysis of the changes of LES pressure after POEM in geriatric patients with achalasia. POEM, peroral endoscopic myotomy; LES, lower esophageal sphincter; MD, mean difference; SD, standard deviation.

events rate related to POEM was $9.0 \%$ and the clinical reflux rate was $17.4 \%$.

The standard POEM procedure was generally performed as follows: (1) submucosal injection and mucosal incision, (2) submucosal tunneling, (3) myotomy, and (4) mucosal entry closure. But for geriatric patients, there are several challenges to perform the procedure. First, it has been reported that the anatomical structure of the esophagus changes with age, including increased nonpropulsive peristaltic contraction, esophageal dilation, and the increase in tertiary contraction resulting in corkscrew esophagus [14]. This could explain why we included studies reporting $11.5-31.5 \%$ of geriatric patients with a sigmoid-shaped esophagus. In this anatomic condition, it would naturally increase the difficulty of operation. Second, geriatric patients tend to have a higher comorbidity burden and reduced physiologic reserve, which led a higher risk of surgical anesthesia $[33,34]$. What is more, if geriatric patients have received other treatment modalities before POEM, it often results in submucous fibrosis, which increases the difficulty of POEM $[35,36]$. In our included studies, there were $42.0 \%(134 / 319)$ geriatric patients receiving previous interventions before POEM. Therefore, the procedure in the geriatric population with these situations should be noted and required experienced endoscopists to operate.

In terms of efficacy, our systematic review showed that the pooled technical success rate of POEM for geriatric patients was $98.1 \%$ and the pooled clinical success rate was $92.5 \%$. Our results were similar to those of adults reported by Barbieri et al. [37] in 2015, which reported the technical and clinical success rates were 97\% (95\% CI, 94-98\%) and 93\% (95\% CI, 90-95\%), respectively.

With regard to safety, our study revealed that the pooled adverse events rate related to POEM was $9.0 \%$ in geriatric patients. Barbieri et al. reported the major adverse events (required medical or surgical interventions) occurred in 14\% (95\% CI, 11-17\%) of adults [37]. In our involved studies, only Chen et al. and Abe et al., respectively, reported one adverse event was graded as severe, associated with a case of cardiac arrhythmia during the procedure $[14,18]$. In addition, the occurrence of adverse events in geriatric patients may be related to a combination of factors, such as physiologic reserve reduced with age, a higher comorbidity burden, and the esophageal tissue changed with age. Overall, POEM is a safe treatment method for geriatric patients. 
As for clinical reflux, it was noted in $17.4 \%$ of patients in our meta-analysis, which is comparable to adult data of POEM, the pooled rate of esophagitis was $13 \%(47 / 354 ; 95 \%$ CI, 10-17\%) [37]. Compared to LHM + Dor fundoplication, Costantini et al. conducted a clinical research which showed that esophagitis was found in $37.4 \%$ of POEM and $15.2 \%$ of Dor fundoplication patients $(p<0.05)$ [38]. Furthermore, Aiolfi et al. performed a meta-analysis which revealed that postPOEM gastroesophageal reflux disease was significantly higher when comparing to LHM [39]. Although proton pump inhibitors could effectively manage clinical reflux after the POEM procedure, appropriate methods still need to develop to decrease the occurrence of postoperative clinical reflux. Interestingly, the fundoplication procedure after POEM reported recently by Inoue et al. could alleviate the clinical reflux rate [40]. In their study, they successfully added the fundoplication procedure after standard POEM and showed that the clinical process after this technical was safe without immediate or delayed complications. Therefore, it might be more beneficial to add the anti-reflux procedure after basic POEM in the future.

We acknowledged that our study had several limitations. First, we included patients $\geq 65$ years in our study. But studies of Chen et al. [14] and Abe et al. [18] involved octogenarians, which seemed to exaggerate the outcome of adverse events because Abe et al. [18] reported that octogenarians had significantly more adverse events with respect to nonoctogenarians. Then, $\mathrm{NIH}$ assessment of the included articles showed that there was an overall fair quality of evidence in our study. However, it is essential to know that the 7 studies we included were not randomized controlled studies, with 2 studies being conference abstracts, which is a very limited level of proof. Furthermore, we have included all the literature of POEM for treatment of geriatric patients with achalasia. However, in adult cohorts' study, there could be a few geriatric patients who we did not catch in the analysis. In addition, the research of Klair et al. reported the POEM for esophageal dysmotility disorders, in which a small number of geriatric patients without achalasia cannot be excluded [17]. Finally, several studies also had missing information on POEM features, such as achalasia type, ASA scores, number of sigmoid-shaped esophagus, myotomy length, operative time, postoperative Eckardt score, and LES pressure, which did not allow us to carry out a more comprehensive analysis.

Role of POEM for Achalasia in Geriatric Patients

\section{Conclusions}

Our current study demonstrated that the POEM was an effective and safe technique for achalasia in geriatric patients. Randomized trials need to be conducted to further compare the efficacy and safety of POEM between geriatric and young patients in the future.

\section{Statement of Ethics}

Our research does not require IRB approval and written consent as no human or animal subjects were used.

\section{Conflict of Interest Statement}

The authors have no conflicts of interest to declare.

\section{Funding Sources}

This study is independent research funded by the following grants: the Medical science and technology plan projects of Zhejiang Province (No. 2017196257), the Youth Foundation of Southwest Medical University (No. 0903-00031099), the doctoral research start-up funding project of the Affiliated Hospital of Southwest Medical University (No. 16229), and the Cooperation Project of Southwest Medical University and Luzhou government (No. 2019LZXNYDJ24).

\section{Author Contributions}

Study conception and design: Xiaowei Tang. Drafting of the manuscript: Chunyu Zhong, Shu Huang, and Huifang Xia. Acquisition of data and critical revision: Shali Tan, Muhan Lü, and Yan Peng. Revision of the manuscript and final approval of the manuscript: Xiaowei Tang.

References

1 Eckardt AJ, Eckardt VF. Treatment and surveillance strategies in achalasia: an update. Nat Rev Gastroenterol Hepatol. 2011;8(6): 311-9.

2 Vaezi MF, Pandolfino JE, Vela MF. ACG clinical guideline: diagnosis and management of achalasia. Am J Gastroenterol. 2013;108(8): 1238-50.

3 Samo S, Carlson DA, Gregory DL, Gawel SH, Pandolfino JE, Kahrilas PJ. Incidence and prevalence of achalasia in Central Chicago, 2004-2014, since the widespread use of highresolution manometry. Clin Gastroenterol Hepatol. 2017;15(3):366-73.

4 Sonnenberg A. Hospitalization for achalasia in the United States 1997-2006. Dig Dis Sci. 2009;54(8):1680-5. 
5 Gennaro N, Portale G, Gallo C, Rocchietto S, Caruso V, Costantini M, et al. Esophageal achalasia in the Veneto region: epidemiology and treatment. Epidemiology and treatment of achalasia. J Gastrointest Surg. 2011;15(3): $423-8$.

6 Boeckxstaens GE, Zaninotto G, Richter JE. Achalasia. Lancet. 2014;383(9911):83-93.

7 Boeckxstaens GE, Annese V, des Varannes SB, Chaussade S, Costantini M, Cuttitta A, et al. Pneumatic dilation versus laparoscopic Heller's myotomy for idiopathic achalasia. N Engl J Med. 2011;364(19):1807-16.

8 Tsuboi K, Omura N, Yano F, Hoshino M, Yamamoto SR, Akimoto S, et al. Identification of risk factors for mucosal injury during laparoscopic Heller myotomy for achalasia. Surg Endosc. 2016;30(2):706-14.

9 Vaezi MF, Pandolfino JE, Vela MF. American College of Gastroenterology clinical guideline: diagnosis and management of achalasia. Am J Gastroenterol. 2013;108:1238-49.

10 Talukdar R, Inoue H, Nageshwar Reddy D. Efficacy of peroral endoscopic myotomy (POEM) in the treatment of achalasia: a systematic review and meta-analysis. Surg Endosc. 2015;29(11):3030-46.

11 Patel K, Abbassi-Ghadi N, Markar S, Kumar S, Jethwa P, Zaninotto G. Peroral endoscopic myotomy for the treatment of esophageal achalasia: systematic review and pooled analysis. Dis Esophagus. 2016;29(7):807-19.

12 Kahrilas PJ, Katzka D, Richter JE. Clinical practice update: the use of per-oral endoscopic myotomy in achalasia: expert review and best practice advice from the AGA institute. Gastroenterology. 2017;153(5):1205-11.

13 Wang X, Tan Y, Lv L, Zhu H, Chu Y, Li C, et al. Peroral endoscopic myotomy versus pneumatic dilation for achalasia in patients aged $\geq 65$ years. Rev Esp Enferm Dig. 2016;108(10): 637-41.

14 Chen YI, Inoue H, Ujiki M, Draganov PV, Colavita P, Mion F, et al. An international multicenter study evaluating the clinical efficacy and safety of per-oral endoscopic myotomy in octogenarians. Gastrointest Endosc. 2018;87(4):956-61.

15 Landi R, Familiari P, Mangiola F, Calì A, D'Aversa F, Bove V, et al. Peroral endoscopic myotomy for the treatment of esophageal motility disorders: baseline characteristics and procedural outcomes in young and elderly patients. Endoscopy. 2018;50(04):S47.
16 Liu XY, Cheng J, Chen WF, Xu MD, Liu ZQ, Wang Y, et al. Effect of peroral endoscopic myotomy in geriatric patients: a propensity score matching study. Surg Endosc. 2020; 34(7):2911-7.

17 Klair J, Hasan Y, Masadeh M, Gerke H, Murali A, Parekh K, et al. Safety and efficacy of peroral endoscopic myotomy (POEM) in patients $\geq 65$ years at a single academic tertiary care center. Am Coll Gastroenterol. 2019; 10(114):S221.

18 Abe H, Tanaka S, Kawara F, Toyonaga T, Ariyoshi R, Sakaguchi H, et al. Comparison of the safety and efficacy of peroral endoscopic myotomy between octogenarians and non-octogenarians. Dig Endosc. 2020 Apr 9;33:11017.

19 Sanaka MR, Chadalavada P, Alomari M, Tang A, Parikh M, Garg R, et al. Peroral endoscopic myotomy is a safe and effective treatment modality for geriatric patients with achalasia. Esophagus. 2020;17(4):484-91.

20 Moher D, Liberati A, Tetzlaff J, Altman DG; PRISMA Group. Preferred reporting items for systematic reviews and meta-analyses: the PRISMA statement. Int J Surg. 2010;8(5): 336-41.

21 Cotton PB, Eisen GM, Aabakken L, Baron TH, Hutter MM, Jacobson BC, et al. A lexicon for endoscopic adverse events: report of an ASGE workshop. Gastrointest Endosc. 2010; 71(3):446-54

22 NIH. Quality Assessment Tool for Before-After Studies with No Control Group. National Institutes of Health Web site. 2014. http:// www.nhlbi.nih.gov/health-pro/guidelines/ in-develop/cardiovascular-risk-reduction/ tools/before-after.

23 Riley RD, Higgins JP, Deeks JJ. Interpretation of random effects meta-analyses. BMJ. 2011; 342: d549.

24 Cochrane Handbook for Systematic Reviews of Interventions [Internet].

25 Richter JE. Achalasia: an update. J Neurogastroenterol Motil. 2010;16(3):232-42.

26 Li CJ, Tan YY, Wang XH, Liu DL. Peroral endoscopic myotomy for achalasia in patients aged $\geq 65$ years. World J Gastroenterol. 2015; 21(30):9175-81.

27 Roll GR, Ma S, Gasper WJ, Patti M, Way LW, Carter J. Excellent outcomes of laparoscopic esophagomyotomy for achalasia in patients older than 60 years of age. Surg Endosc. 2010; 24(10):2562-6.

28 Vaezi MF, Pandolfino JE, Vela MF. American College of Gastroenterology clinical guideline: diagnosis and management of achalasia. Am J Gastroenterol. 2013;108:1238-49.
29 Zárate N, Mearin F, Baldovino F, Armengol JR, Malagelada JR. Achalasia treatment in the elderly: is botulinum toxin injection the best option? Eur J Gastroenterol Hepatol. 2002; 14(3):285-90.

30 Richter JE, Boeckxstaens GE. Management of achalasia: surgery or pneumatic dilation. Gut. 2011;60(6):869-76

31 Inoue $\mathrm{H}$, Sato $\mathrm{H}$, Ikeda $\mathrm{H}$, Onimaru M, Sato $\mathrm{C}$, Minami H, et al. Per-oral endoscopic myotomy: a series of 500 patients. J Am Coll Surg. 2015;221(2):256-64.

32 Barbieri LA, Hassan C, Rosati R, Romario UF, Correale L, Repici A. Systematic review and meta-analysis: efficacy and safety of POEM for achalasia. United European Gastroenterol J. 2015;3(4):325-34.

33 Finlayson EV, Birkmeyer JD. Operative mortality with elective surgery in older adults. Eff Clin Pract. 2001;4(4):172-7.

34 Linn BS, Linn MW, Wallen N. Evaluation of results of surgical procedures in the elderly. Ann Surg. 1982;195(1):90-6.

35 Smith CD, Stival A, Howell DL, Swafford V. Endoscopic therapy for achalasia before Heller myotomy results in worse outcomes than heller myotomy alone. Ann Surg. 2006; 243(5):579-6.

36 Snyder CW, Burton RC, Brown LE, Kakade MS, Finan KR, Hawn MT. Multiple preoperative endoscopic interventions are associated with worse outcomes after laparoscopic Heller myotomy for achalasia. J Gastrointest Surg. 2009;13(12):2095-103.

37 Barbieri LA, Hassan C, Rosati R, Romario UF, Correale L, Repici A. Systematic review and meta-analysis: efficacy and safety of POEM for achalasia. United European Gastroenterol J. 2015;3(4):325-34.

38 Costantini A, Familiari P, Costantini M, Salvador R, Valmasoni M, Capovilla G, et al. Poem versus laparoscopic Heller myotomy in the treatment of esophageal achalasia: a casecontrol study from two high volume centers using the propensity score. J Gastrointest Surg. 2020;24(3):505-15.

39 Aiolfi A, Bona D, Riva CG, Micheletto G, Rausa E, Campanelli G, et al. Systematic review and Bayesian network meta-analysis comparing laparoscopic Heller myotomy, pneumatic dilatation, and peroral endoscopic myotomy for esophageal achalasia. J Laparoendosc Adv Surg Tech A. 2020;30(2):147-55.

40 Inoue $\mathrm{H}$, Ueno $\mathrm{A}$, Shimamura $\mathrm{Y}$, Manolakis A, Sharma A, Kono S, et al. Peroral endoscopic myotomy and fundoplication: a novel NOTES procedure. Endoscopy. 2019;51(2): 161-4. 